\title{
O PROFESSOR CANDIDO MOTA FILHO NA CÁTEDRA DE DIREITO PUBLICO CONSTITUCIONAL
}

Perante a Congregação dos Professores, tomou posse, dia 8 de agosto de 1951, da catedra de Direito Público Constitucional, o professor Ciândido Mota Filho. Instalada a sessão solene, o diretor da Faculdade de Direito, professor Braz de Sousa Arruda, nomeou os professores Teotônio Monteiro de Barros Filho e Miguel Reale para, em nome da Congregação, introduzirem o professor Cândido Mota Filho no salão nobre da Faculdade, para o compromisso regimental. Ao entrar na sala, o novo catedrático da academia do largo de S. Francisco foi saudado por vibrante salva de palmas, partidas dos integrantes da Congregação e das numerosas pessoas presentes à solenidade.

Pelo secretário Flávio Mendes foi lido o decreto pelo qual o governo do Estado, tendo em vista o concurso há pouco realizado, procedia à nomeação do professor Cândido Mota Filho para catedrático da Faculdade de Direito. A seguir, o sr. Cândido Mota Filho prestou o compromisso regimental, que toda a congregação ouviu de pé.

Saudando o novo catedrático, usou da palavra, o diretor da Faculdade de Direito, professor Braz de Sousa Arruda, pronunciando expressivo discurso, em que ressaltou a sua satisfação em acolher um novo membro da tradicional academia, augurando-lhe a maior soma de felicidades no decorrer de suas atividades, como catedrático da importante disciplina que iria regér. 


\section{FALA O NOVO CATEDRÁTICO}

Agradecendo as manifestações de simpratia que recebera dos presentes, o professor Cândido Mota Filho pronunciou o seguinte discurso:

"Só agora, meus ilustres Mestres, é que posso compreender que, em determinado momento da vida, somos como um Ulisses inquieto, desembarcando em Itaca, após grandes e gravíssimos perigos! É essa a impressão desusada que tenho, neste instante, como se estivesse descendo em terra minha. Na emoção da chegada, com a sôfrega saudade das coisas familiares, - confundem-se, na mesma ternura e alvoroço, as imagens do presente, com as recordações do passado...

Sinto-me cercado aquí, ao conquistar o posto que era suprema aspiração de minha vida cultural, não só pela vossa honrosa e benévola generosidade, como também pela presença imortal dos grandes apóstolos desta Casa, por essa Congregação imperecivel, que acompanha os gestos de nossas atitudes, em meio dos escarcéus das paixões desumanas.

Venho assumir uma cadeira de incomparável responsabilidade. Sinto-a em toda plenitude, pelo sangue que lateja em meu peito e como consequência de minhas horas de estudo e de meditação; sinto-a como advogado, no trato dos casos que a profissão oferece; como jornalista, em contato imediato com os acontecimentos, no mistér delicado e difícil de analisar os conflitos entre os ideais e a realidade; como político, no parlamento, nos comícios, na administração pública, na própria carne com as insuficiências e as virtudes das instituições consagradas.

Por está cátedira passaram grandes mestres, que souberam honra-la è engrandecê-la. Relembro aquí, entre os mortos, aquêle que esteve mais perto de mim, o saudoso Herculano de Freitas, que paraninfou a minha turma. Ainda 
guardamos, todos nós, que fomos seus alunos, sua magistral oração na hora solar da nossa formatura. Foi Herculano de Freitas, com sua larga experiência, um professor que sabia pôr, em suas lições, com a segurança de seu saber, o gosto da vida e compreender, de imediato, os estremecimentos que já abalavam, de vez em vez, em seu tempo, as bases do nosso edifício constitucional. Como bom republicano, que sinceramente acreditava no aperfeiçoamento dos homens e de suas criações, proclamava, como um benefício, a evolução normal e progressiva das instituições e das leis. Porém, ninguém mais do que êle compreendia a substância conservadora do direito e ninguem mais enamorado do que êle, das tradições, de nossa vida política. E, por ser assim, um temperamento acolhedor, humano e compreensivo, é que podia, em 1919, fixar como tema principal de sua oração de paraninfo a ameaça que surgia no horizonte para a vida do direito.

Naquele instante alviçareiro de minha adolescência, não podia jamais pensar que a tempestade por Herculano de Freitas prenunciada, caisse por sôbre nossas cabeças, escurecendo as luzes do mundo, quando a sua cátedra ilustre e venerável vinha para as minhas mãos! ”

A minha geração com efeito, tem a ventura e a desventura de suportar talvez a maior crise que desabou sôbre o Ocidente. Ela assistiu duas guerras mundiais, à ruina de cidades seculares, à queda de impérios poderosos, às perseguições raciais, e exacerbações nacionalistas, à consagração da violência como conduta social, o apoio pavoroso $\hat{a}$ política concentracionaria, à repulsa aos velhos princípios ou ao desconhecimento de todos os princípios, que foram encobertos, com as repetidas férias da legalidade.

Para ambicionar a cátedra de Direito Constitucional tinha eu o dever de fazer uma profissão de fé e de afirmar, como afirmei, a necessidade de preservar-se a autenticidade desse direito, pelo conhecimento e trato de suas raizes, porque só assim é que poderiamos, pelo respeito ao passado, 
compreender na sua amplitude, as aspirações da atualidade. Por certo que, nesse ramo do direito, não podemos ficar só nas velhas fórmulas e nos velhos compêndios. Num momento de repudios despropositados, não podiamos esquecer a experiência dos tempos onde mergulham as razões do constitucionalismo. E Herculano de Freitas, na oração que aquí recordo, depois de acentuar que era necessário procurar o équilíbrio que o direito réaliza numa nova combinação dos elementos sociais, para que a nossa sociedade não fosse eliminada como incapaz, como aconteceu com a nobreza em Franca, - dirigia-se aos professores, dizendo: - "Não se ensina só para analisar textos e para explicar matéria técnica, mas também e muito para gerar e despertar idéias e sentimentos". A missão é efetivamente em nossos dias, das mais delicadas Quando Paul Bourget procurou acentuá-la, em seu romance "Le Disciple", no momento em que o relativismo kanteano estava produzindo seus primeiros efeitos, longe estávamos dos destinos de uma época onde impera, nó dizer de Julien Benda, "o ódio político" e onde o rumor trágico das divergências podem se assemelhar, para os mais otimistas, a uma imensa e incomparável oficina onde se elabora um mundo.

Foi esta, aliás, a lição que aprendí nesta Casa. E não you, uma só vez, deixar de repetí-la aos meus alunos, para que conheçam a verdade, mantenham acesa a chama de suas convicções e não sofram o desengano que lhes of erecerá uma paisagem mundial sem caminhos e iluminações.

Conhecendo a utilidade sem par da vossa ilustre companhia, meus caros professores, - onde se unem e se estimulam a capacidade, a ilustração e a devoção docente, - não irei sofrer daquele perigoso escrúpulo a que se referia o: Padre Antônio Vieira, escrupuloso que levou o dubitativo Pilatos para as fogueiras do Inferno!

Caminharei convosco, integrado no destino comum de leviar avante o bom nome e a glória da Faculdade de Direito 
de São Paulo e de lutar, em todas as lutas, pelo prestígio sempre crescente do ensino jurídico, em nossa terra bem amada".

\section{DADOS BIO-BIBLIOGRÁFICOS DO NOVO CATEDRÁTICO}

Nasceu em 16 de setembro de 1897, na Capital de S. Paulo, filho do prof. Cândido Mota e de d. Clara Amaral Mota. Fez seus estudos primários na Escola Modelo Caetano de Campos e no Grupo do Arouche, em S. Paulo e o secundário noColégio Santo Inácio de Loyóla, no Rio e no ginásio Nogueira da Gama. Fez o seu curso jurídico na Faculdade de Direito, fazendo parte da turma que se formou em 1919.

Exerceu vários cargos públicos de alta responsabilidade, o magistério e o jornalismo. Iniciou sua vida política como juiz de paz na capital paulista, foi deputado estadual, membro da constituinte de 1934, onde fez parte da Comissão de Constituição e Justiça, tendo sido autor de vários projetos de lei, entre êles o que veda a publicação de nome de menores envolvidos em crimes, o que se refiere às cidades tradicionais paulistas. Foi membro da comissão elaborada do ante-projeto sôbre a organização dos Serviços Sociais do Estado e relator do mesmo na Assembléia. Fez parte de comissões encarregadas da elaboração de vários projetos, tendo participado, como secretário da Comissão encarregada da revisão do projeto de Código Criminal da República, comissão presidida pelo senador Alcântara Machado. Fez parte da comissão encarregada da elaboração do projeto de lei sôbre proteção à familia, presidida pelo ministro Francisco Campos, onde apresentou um projeto sôbre o Departamento Nacional da Criança. Fez parte da Comissão que elaborou o projeto sôbre o Departamento Estadual da Criança e daquele que elaborou o projeto de reforma da Penitenciária do Estado. Durante a Constituinte Nacional 
de 1934, presidiu, no escritório técnico da Bancada Paulista, a parte referente aos assuntos jurídicos.

Advogado do Patronato Agrícola do Estado, na Prefeitura Municipal de S. Paulo, diretor do Reformatório Modelo e do Serviço da Reeducação, diretor do Departamento de Imprensa e Propaganda foi oficial de gabinete do prefeito Antônio Carlos de Assunção e chefe do gabinete do Ministro Honório Monteiro, na pasta do Trabalho onde exerceu o cargo de Ministro interino.

Jornalista, ingressou em 1917 na redação do "Correio Paulistano", tendo, em seguida, sido o diretor do "S. Paulo Jornal", redator da Folha da Manhã, do "Diario de S. Paulo" e redator chefe do "Correio Paulista", sendo colaborador efetivo de várias revistas literárias e científicas, nacionais e extrangeiras. Foi também diretor da revista "Politica" e da revista "Planalto".

Livre docente de Direito Penal da Faculdade de Direito de S. Paulo e, depois livre docente de Direito Constitucional, e em consequência da docência, por proposta unânime da Congregação, professor contratado dessa cadeira, tendo afinal sido nomeado catedrático por concurso regular.

Publicou várias obras, tais como "O Romantismo", "A vida de Bernardino de Campos". "O caminho de três agonas", "Rui, esse desconhecido", "Discurso acadêmico", quando ingressou na Academia Paulista de Letras, onde exerce o cargo de secretário geral. Publicou várias obras jurídicas, tais como "A função de punir", "O tratamento de menores delinquentes", A defesa da infância contra o crime", "Da premeditação", "Do estado de necessidade", "O poder executivo e as ditaduras constitucionais", "A nomeação dos prefeitos das capitais", "Fundamentos políticos da Constituição". 